THE INTERNATIONAL

REVIEW OF RESEARCH IN

OPEN AND DISTANCE LEARNING

\title{
Assumptions and Challenges of Open Scholarship
}
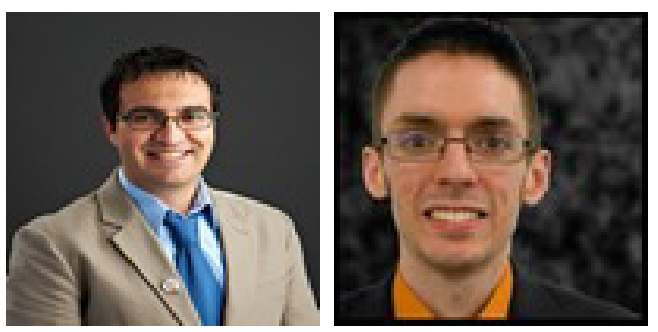

George Veletsianos and Royce Kimmons University of Texas at Austin, USA

\section{Abstract}

Researchers, educators, policymakers, and other education stakeholders hope and anticipate that openness and open scholarship will generate positive outcomes for education and scholarship. Given the emerging nature of open practices, educators and scholars are finding themselves in a position in which they can shape and/or be shaped by openness. The intention of this paper is (a) to identify the assumptions of the open scholarship movement and (b) to highlight challenges associated with the movement's aspirations of broadening access to education and knowledge. Through a critique of technology use in education, an understanding of educational technology narratives and their unfulfilled potential, and an appreciation of the negotiated implementation of technology use, we hope that this paper helps spark a conversation for a more critical, equitable, and effective future for education and open scholarship.

Keywords: Openness; open scholarship; digital scholarship 


\section{Assumptions and Challenges of Open Scholarship}

Openness in a variety of educational and scholarly practices has gained wide interest and attention in recent years (Wiley, 2006; Wiley \& Hilton, 2009). Activities associated with openness are often envisioned to occur within widely accessible online venues such as social media, and might include such activities as open teaching, the production and dissemination of open educational resources, publishing in open access journals, keeping a professional blog, and sharing of research data in online venues. In this paper, we will use the term open scholarship to refer to teaching and research practices that espouse openness and we will refer to those scholars who participate in such practices as being part of the open scholarship movement.

Many scholars hope and anticipate that open practices will broaden access to education and knowledge, reduce costs, enhance the impact and reach of scholarship and education, and foster the development of more equitable, effective, efficient, and transparent scholarly and educational processes. Wiley and Green $(2012$, p. 88) note that "only time will tell" whether practices of open scholarship will transform education or whether the movement "will go down in the history books as just another fad that couldn't live up to its press." Given the emerging nature of such practices, educators are finding themselves in a position in which they can shape and/or be shaped by openness (Veletsianos, 2010). The intention of this paper is (a) to identify the assumptions of the open scholarship movement and (b) to highlight challenges associated with the movement's aspirations of broadening access to education and knowledge. The goal of this paper is not to frame open scholarship as a problematic alternative to the status quo. Instead, as we see individuals, institutions, and organizations embrace openness, we have observed a parallel lack of critique of open educational practices. We find that such critiques are largely absent from the educational technology field, as members of the field tend to focus on the promises of educational technologies, rarely pausing to critique its assumptions. Selwyn (2011b, pp. 713) even charges that our field's inherent positivity "limits the validity and credibility of the field as a site of serious academic endeavour." Our intention is to spark a conversation with the hopes of creating a more equitable and effective future for digital education and scholarship. To this end, this paper is divided into three major sections. First, we review related literature to introduce the reader to the notion of open scholarship. Next, we discuss the assumptions of openness and open scholarship. We then identify the challenges of open scholarship and discuss how these may limit or problematize its outcomes.

\section{Review of Related Literature}

We view open scholarship as a collection of emergent scholarly practices that espouse openness and sharing. Boyer's (1990) framework of scholarship is often used as a starting point for defining scholarly practices in the digital age, and a number of authors have sought to update Boyer's model to reflect contemporary thinking related to scholarly practice (e.g., Garnet \& Ecclesfield, 2011; Heap \& Minocha, 2012; Pearce et al., 2010; Weller, 2011). Nonetheless, there appears to be little consensus in the field about what exactly constitutes open 
scholarship. In this paper, we take an inclusive approach to open scholarship and consider it to take three major forms: (1) open access and open publishing, (2) open education, including open educational resources and open teaching, and (3) networked participation. In our previous work, we have discussed networked participatory scholarship, which is the third component of open scholarship and refers to scholars' uses of online social networks to share, critique, improve, validate, and enhance their scholarship (Veletsianos \& Kimmons, 2012). We are taking an inclusive approach to open scholarship because we believe that this is reflective of current scholarly practice. All three manifestations noted above are instances of open scholarship, but they are enacted or made visible in different forms. Within our frame of understanding, open scholarship is a set of phenomena and practices surrounding scholars' uses of digital and networked technologies underpinned by certain grounding assumptions regarding openness and democratization of knowledge creation and dissemination.

Next, we discuss what open scholarship has come to look like and by laying out some of the core, shared assumptions of these manifestations, we will provide the groundwork for a discussion related to limitations, problems, or unaddressed issues within the open scholarship movement.

\section{What Does Open Scholarship Currently Look Like?}

Discussions of openness gained traction after Friedman (2005) argued that digital technologies and open sourcing of software had helped to connect knowledge centers across the globe, thereby "flattening" the world and helping to create an even playing field between nations, groups, and individuals in a variety of ways (e.g., economics, research, etc.). More recently, Bonk (2009) built upon this idea and argued that digital technologies are specifically acting to democratize the education process. He argues that "anyone can now learn anything from anyone at anytime" and believes that this shift in the educational milieu offers a "new hope for educating citizens of this planet" (pp. 7-8). Similarly, proponents of the open scholarship movement have argued that by participating with emerging technologies, scholars can help to democratize knowledge production and dissemination via public online venues such as blogs and social networking sites. For example, Kumashiro et al. (2005) suggested that "technological changes are going to flood how we currently think about, do, and represent research" (p. 276), Greenhow, Robelia, and Hughes (2009) posited that "participatory internet technologies... have the potential to change the way academics engage in scholarship" (p. 252), and Garnett and Ecclesfield (2011) argued that social media could empower scholars to "co-create" knowledge through networks.

These observations and projections have taken form in a variety of emergent open practices amongst scholars, including (1) publishing in open access journals and submitting publications and data to institutional or national repositories; (2) maintaining digital presence via blogs, microblogs, personal Web sites, and social networking sites; and (3) providing and making use of open educational resources and leading and engaging in open courses and open teaching practices. We give a brief overview of each of these and then discuss some 
underlying assumptions and characteristics that they share.

\section{Open Access Journals and Institutional Repositories}

As increasing numbers of print media are being replaced by digital equivalents and as issues of copyright infringement and illegal sharing become more common, scholars have begun questioning the traditional publication process and sharing their work more freely through online venues. Open access (OA) publishing has grown rapidly over the last fifteen years (Laakso et al., 2011), and OA journals have quickly arisen as

- an option for scholars to publish their work so that anyone with an Internet connection can access scholarly work without facing traditional financial, legal, or technical barriers;

- a means for limiting potentially abusive publisher behaviors; and

- a way of returning control of scholarly work to the authors (c.f. Furlough, 2010; Wiley \& Green, 2012).

Researchers have also found open access to be financially prudent for universities and institutions interested in starting a journal (Getz, 2005; Houghton \& Sheehan, 2006) and have found that OA journals may produce a greater impact (in terms of readership and citations) than non-open access (NOA) journals (Brody \& Harnad, 2004; Evans, 2008; Evans \& Reimer, 2009; Eysenbach, 2006; Getz, 2005; Kurtz \& Brody, 2006; Lawrence, 2001; Lewis, 2006; Norris et al., 2008). Further, researchers have found that some OA journals can attain a high level of impact within just a few years of launch and that OA journal articles are twice as likely to be cited as their NOA peers (Brody \& Harnad, 2004; Kurtz \& Brody, 2006).

Though a causal relationship between a journal's impact and its OA status alone is not supported by research findings (Craig et al, 2007; Davis, 2006; Davis \& Fromerth, 2007; Gargouri et al., 2010; Henneken et al., 2006; Moed, 2006) and "OA will not make an unuseable (hence unciteable) paper more used and cited” (Gargouri et al., 2010, p. 18), it becomes clear that "wherever there are subscription-based constraints on accessibility, providing OA will increase the usage and citation of the more useable and citeable papers" (Gargouri et al., 2010, p. 18). As a result, Getz (2005, p.17) anticipates that such increased usage may lead to scholarship being "of wider influence in our society and across the planet," forecasting that "[open scholarship] researchers are likely to be more productive and students will learn more by using open scholarship" and that "within ten years, open journals are likely to dominate scholarly communication." Empirical evidence from Hajjem, Harnad, and Gingras (2005) supports this argument, as these authors found that 1.3 million NOA papers in ten disciplines that were self-archived between 1992 and 2003 have had more citations than papers that were not self-archived.

In addition to OA publications, many scholars have found benefit in sharing their data and manuscripts via institutional or national repositories in hopes of improving research and development (Houghton et al., 2009; Lynch, 2003) and making tax-funded research (often 
conducted by public universities) available to the public (Kuchma, 2008). Ukraine, for instance, has moved to a mandated OA system for all publicly funded research, and there has been similar interest in the United States (Kuchma) and in projects funded by the European Union (European Commission, 2012).

\section{Digital Presence through Blogs, Microblogs, Personal Web Sites, and Social Networking Sites}

Web 2.o technologies have helped to make Web site creation and self-publishing seamless and easy, contributing to an increasing incidence of individual presence online. A simple web search will reveal personally maintained Web sites or blogs for a number of education scholars, prominent and emerging alike. In addition, social networking sites (SNS) have recently risen in popularity to such an extent as to make platforms like Facebook, Twitter, and LinkedIn common household and editorial topics. A recent survey in the United States by the Pew Internet \& American Life Project (Hampton et al., 2011) for example reports that $39 \%$ of adult Internet users (30+ years of age) currently use an SNS and that on a typical day $25 \%$ of all adult internet users utilize an SNS. Such data are not limited only to the US. In Canada for example, about $60 \%$ of individuals who use the Internet have a profile on an online social networking site (Ipsos, 2011). Higher education faculty have also adopted SNS in growing numbers. Moran, Seaman, and Tinti-Kane (2011), for instance, found that amongst nearly two thousand higher education faculty surveyed, well over 90\% were at least aware of the major SNS and over 50\% of all surveyed visited Facebook in the previous month, with over $40 \%$ posting something to the SNS in that time.

Use of these digital spaces may reflect an interest in having debate platforms for scholars who seek to live as public intellectuals, recording and sharing logs of research, or offering spaces around which critical discussions of the scholarly enterprise can occur (Kirkup, 2010; Walker, 2006). By maintaining a web presence, scholars may express their opinions, solicit feedback, reflect, share information pertaining to their professional practice, network with colleagues, reach multiple audiences, and cultivate their identity as scholars (Veletsianos, 2012; Kjellberg, 2010; Martindale \& Wiley, 2005; Nardi, Schiano, \& Gumbrecht, 2004).

While scholars have also considered the pedagogical value of SNS within the classroom (Veletsianos \& Navarrete, 2012b; Bull et al., 2008; Greenhow \& Robelia, 2009a, 2009b; Mazer et al., 2007; Mazer et al., 2009; Munoz \& Towner, 2009), in a survey conducted by Moran et al. (2011), it was found that $45 \%$ of higher education respondents use Facebook for professional, non-classroom purposes. Such nonclassroom uses of SNS may reflect an interest in online social grooming or using online tools as "a means to improve one's reputation and status as well as access to resources and social and practical solidarity" (Tufekci, 2008, p. 546) and are indicative of a larger cultural movement toward online culture building and connection such that, for many scholars, it may now be "hard to think of a life offline" (Beer, 2008, p. 521).

Nevertheless, the tendency to use SNS in organized professional contexts appears to be lim- 
ited. For example, online science-related journals that have experimented with community commenting platforms to support scholarly discussion around articles have exhibited a low volume of comments (Neylon \& Wu, 2009), suggesting that though culturally we have come to use SNS for a variety of purposes, enthusiasm for these media has not fully carried over to professional scholarly purposes.

\section{Open Educational Resources, Open Teaching, and Open Courses}

The open educational resources (OER) and open teaching movements seek "to provide open access to high quality digital educational material" (Caswell, et al., 2008) in a "spirit similar to that of free and open software" (Wiley, 2003 99) and OA journals. UNESCO (2002) defines OER as "the open provision of educational resources, enabled by information and communication technologies, for consultation, use and adaptation by a community of users for non-commercial purposes" (p. 22), and OECD (2007) defines OER as "digitised materials offered freely and openly for educators, students and self-learners to use and reuse for teaching, learning and research" (p. 10). Major projects and examples that could fall under the umbrella of OER include OER Commons, MIT OpenCourseWare, the Wikimedia Foundation, Project Gutenberg, Creative Commons, Flat World Knowledge, and Saylor. org. Though there is no universally accepted definition of what constitutes OER, the overarching characteristics of OER are "resources that reside in the public domain or have been released under an intellectual property license that permits their free use or re-purposing by others" (Atkins, Seely Brown, \& Hammond, 2007, p. 4). The OER movement has gained worldwide attention as a wide variety of governmental, institutional, and philanthropic organizations have adopted OER policies and have supported OER development (Hoosen, 2012), and it is believed that such practices have the potential to provide "individuals who might otherwise never have the opportunity to experience post-secondary learning a free and open chance to participate" (Wiley \& Green, 2012, p. 88). Though still in its infancy, the OER movement has exhibited some positive outcomes (Wiley, 2010) though not necessarily a "discernable impact" (Wiley, Hilton, Ellington, \& Hall, 2012). For instance, an exploratory investigation of open textbook adoption in the state of Utah by Wiley et al. (2012) found significant cost reductions that were accompanied by no significant changes in learning outcomes as measured by standardized test scores.

Closely related to the OER movement is the practice of creating open courses that a number of faculty members and universities have begun adopting. Similar to MIT's OpenCourseWare project, numerous universities have made available course materials to the public in the form of syllabi, video lectures, audio recordings, course notes, presentation files, and other learning objects. Building off of this idea, institutions have also recently begun offering a type of free online course referred to as massive open online courses (MOOCs). In these courses, primary activities emphasize connected learning through active aggregation of information, "remixing" aggregated information through building relations to earlier experiences, repurposing information by generating digital artifacts, and sharing (Kop \& Fournier, 2010). The major difference between MOOCs and OER is that the former are intended to serve as online learning environments that support learners in the edu- 
cational process (e.g., providing feedback, completing assignments, sharing information, etc.), rather than merely making content available to them. As Fini (2009) explains, "open online courses may be considered to be a special type of OER, which solves the problem of the lack of interaction that is typical of most OER initiatives," and "the real potential of an OOC [open online course] is to be found in the emergence of learning networks among participants in a many-to-many relationship, rather than the traditional one-to-many model of interactions between a teacher and his or her students" (p. 3). Prominent examples of MOOCs include the Connectivism and Connective Knowledge (CCKo8) course offered by Siemens and Downes (2008), Jim Groom's (2011) Digital Storytelling course (\#ds106) at the University of Mary Washington, Thrun and Norvig's (2011) Introduction to Artificial Intelligence course at Stanford, MITx's Circuits and Electronics course (2012), and the courses offered by educational startups such as Coursera, Udacity, and EdX.

\section{What Do these Practices Say about Open Scholarship?}

Given these examples of open scholarship, we should be able to recognize some common themes and assumptions about openness, sharing, and Internet technologies that unite such practices. First, open scholarship has a strong ideological basis rooted in an ethical pursuit for democratization, fundamental human rights, equality, and justice. As the Budapest Open Access Initiative (2002) explains, the aim of openness is "building a future in which research and education in every part of the world are ... more free to flourish," thereby reflecting ideals of democracy, free speech, and equality. Caswell, Henson, Jensen, and Wiley (2008) further explain this ideological basis with a statement of belief:

We believe that all human beings are endowed with a capacity to learn, improve, and progress. Educational opportunity is the mechanism by which we fulfill that capacity. Therefore, free and open access to educational opportunity is a basic human right, ... [and] we have a greater ethical obligation than ever before to increase the reach of opportunity. (p. 26)

Directing these desires for ensuring basic human rights, transparency, and accountability is a sense of justice or fairness in scholarly endeavors. Based on this ideological foundation, openness and sharing in scholarship are seen as fundamentally ethical behaviors that stand as moral requirements for any who value ideals of democracy, equality, human rights, and justice.

Second, open scholarship emphasizes the importance of digital participation for enhanced scholarly outcomes. Arguments for openness tend to focus on addressing the shortcomings and limitations of current institutionalized practices through faculty participation in online spaces. For instance, Greenhow, Robelia, and Hughes (2009, p. 253) argue that Web 2.0 "tools might positively affect-even transform-research, teaching, and service responsibilities-only if scholars choose to build serious academic lives online, presenting 
semipublic selves and becoming more invested in and connected to the work of their peers and students." Throughout these arguments for openness, the undesirable alternative is depicted as being "closed" or unresponsive to calls for equity, sharing, and transparency.

Third, open scholarship is treated as an emergent scholarly phenomenon that is co-evolutionary with technological advancements in the larger culture. Though ideals espoused in the first assumption are not new developments, their reintroduction into and re-emphasis in discussions of scholarship come in conjunction with the development and diffusion of a variety of social technologies. As Wiley and Green (2012) point out, open practices "allow the full technical power of the Internet to be brought to bear on education” (p. 82), and though causal relationships between technology developments and social trends are multidimensional, historical precedents suggest that social trends evolve in conjunction with technology development in a negotiated and co-evolutionary manner (cf. Veletsianos \& Kimmons, 2012; Binkley, 1935). Thus, when discussing openness in scholarship, technology must be seen as both being an actor (i.e., influencing changes in scholarly culture and thereby influencing cultural behaviors) and being acted upon (i.e., being influenced by scholarly and other cultures and thereby reflecting cultural behaviors).

Finally, open scholarship is seen as a practical and effective means for achieving scholarly aims that are socially valuable. Such aims might range from ideological values (as mentioned above) to a variety of others including reduced cost of delivery, improved efficiency, greater accuracy, and so forth. For instance, one argument in favor of OA journals is that "the cost savings alone are likely to be sufficient to pay for open access journal publishing or self-archiving, independent of any possible increase in returns to $\mathrm{R} \& \mathrm{D}$ that might arise from enhanced access" (Houghton et al., 2009, p. XIX). Similar arguments have been made about improved research efficiency in sharing data sets (Trinidad et al., 2010), increasing the reach of universities via MOOCs (Carson \& Schmidt, 2012), and using SNS for research purposes (Greenhow, 2009). Considering an educational perspective, such efficiency may also have pedagogical value because as Wiley and Green (2012) argue, "Education is a matter of sharing, and ... [open practices] enable extremely efficient and affordable sharing" (p. 82). In their view, "those educators who share the most thoroughly of themselves with the greatest proportion of their students" are seen as successful (p. 82). From this perspective, openness is seen as an effective vehicle for achieving various scholarly goals like affordability, efficiency, accuracy, accessibility, sustainability, dissemination, and effective pedagogy.

\section{The Need for a Critical Examination of our Practices}

Empirical findings on researchers' and instructors' digital, networked, and open participation and practices have so far been minimal and have largely indicated that the use of participatory technologies for learning and scholarship is rife with tensions rather than realized transformative potential (Veletsianos \& Kimmons, in press; Selwyn 2011a). Still, although we may have an early understanding of why individuals may not engage in open practices, we have not paused to examine potential unintended consequences of embracing activities associated with open scholarship. 
A few reasons have already been proposed in the literature that may describe why scholars might not engage with digital scholarship. First, higher education faculty may be more inclined to use "traditional" technologies in their practice, such as email, than students (Roblyer, McDaniel, Webb, Herman, \& Witty, 2010), and thereby may not necessarily capitalize on networked opportunities for scholarship. A second reason may be due to the relative newness of the concept of open scholarship and specialized social media tools targeting scholars, as social networking sites for academics (e.g., Mendeley and Academia.edu) have only been available since about 2007. As with every emerging technology used in education, it takes time for these tools to be evaluated, adopted, and appropriated into wide practice (Veletsianos, 2010). Finally, Zaugg, West, Tateishi, and Randall (2011, p. 32) argue that widespread use of such tools may be hindered because scholars might (a) perceive social media as an unnecessary time commitment and (b) "hesitate to openly post their developing research lest they get pre-empted by another researcher or receive public criticism for their still-evolving research.”

However, we see a pressing need for a critical examination of open scholarly practices, because the dominant educational technology narratives embraced in the field present an overwhelmingly positive picture of technology use in education that we believe is detrimental to our future. The promise of technology revolutionizing education has persisted since the 1930 (Mishra, Koehler, \& Kereluik, 2009), though contemporary narratives may include "Web 2.0 technology as user-generated and hence emancipatory, or of learning analytics as allegedly leading to efficient, personalised teaching and learning, or of technology as implicitly progressive” (Hall, 2011, ๆ14). Selwyn (2011b) even charges that, as a field, we need to be more negative to be taken more seriously. We believe that it is through (a) critiques of technology use in education, (b) an understanding of educational technology narratives and their unfulfilled potential, and (c) an appreciation of the complex and negotiated implementation of technology use 'on the ground' that our field will become a site of evaluative, rather than optimistic, discourse about the relationship between technology, education, and scholarship. In the words of Hall (2011, ๆ11), "in order to understand our present position, and to develop alternatives that matter, we need stories and metaphors and critiques of where we are."

\section{Researcher Positionality}

Prior to explaining the challenges facing openness and open scholarship, it is important to clarify our position with respect to these issues so that the reader better understands our frame of reference and the validity of our arguments. Both authors are actively involved in researching emerging technologies (e.g., social media), technology-enhanced scholarship, and emerging forms of learning and participation. In addition, we both believe that various degrees of openness are worthwhile for scholars and educators, and we practice openness in our own work through our own blogs, our participation in social media, our sharing of OER, our publishing in open access journals when we feel a journal is appropriate for our work, and our self-archiving of our publications in ways that allow others to access them in an open manner. We also recognize that open scholarship challenges cultural, social, publishing, and institutional norms, thereby facing institutional obstacles and contesting 
corporate interests. Finally, we also believe that the relationship between technology and practice is negotiated in that technology shapes practice and practice shapes the way technology is used. This belief provides part of the impetus for writing this paper as we believe that technologies shape the ways we enact openness while at the same time our beliefs, understanding, and actions pertaining to openness will shape how we use technology.

\section{Challenges of Openness and Open Scholarship}

In the preceding sections, we highlighted some core assumptions of the open scholarship movement. While we believe that open scholarship tackles deficiencies, injustices, and problems of the status quo, it is imperative to clarify its pitfalls and challenges so that educators, researchers, and administrators can consider and address them. We discuss these issues in detail below in the context of each assumption. Table 1 summarizes these challenges with respect to each assumption.

Table 1

Assumptions and Challenges facing Open Scholarship

Common themes and assumptions
Open scholarship has a strong ideo-
logical basis rooted in an ethical
pursuit for democratization, funda-
mental human rights, equality, and
justice

Open scholarship emphasizes the importance of digital participation for enhanced scholarly outcomes

Open scholarship is treated as an emergent scholarly phenomenon that is co-evolutionary with technological advancements in the larger culture

Open scholarship is seen as a practical and effective means for achieving scholarly aims that are socially valuable

\section{Challenges}

Are these ideals essential components of the open scholarship movement or are they merely incidental to those who are pioneering the field?

Scholars need to develop an understanding of participatory cultures and social/digital literacies in order to take full advantage of open scholarship.

Need to redesign university curricula to prepare future scholars to account for the changing nature of scholarship.

Technology both shapes and is shaped by practice.

Technology is not neutral, and its embedded values may advance tensions and compromises (e.g., flat relationships, homophily, filter bubbles).

Open scholarship introduces new dilemmas and needs (e.g., personal information management challenges; social stratification and exclusion). 


\section{Assumption \#1: Ideals of Democratization, Human Rights, Equality, and Justice}

Though few would argue against framing practices around ideals such as democratization, human rights, equality, and justice, it is presently unclear whether these ideals are essential components of the open scholarship movement or are merely incidental to those who are pioneering the field. That is, at the moment, such scholarly practices may largely reflect the values of early adopters who already engage in them, and these values may not be held as inviolate, or even important, by others who begin replicating them. For example, Cohen (2007, 94) presents a list of fourteen characteristics that describe "social scholars" (e.g., "a social scholar initiates or joins an online community devoted to her topic, using any of a number of social software services or tools"). Burton (2009, 95) describes the "Open Scholar" as someone who "makes their intellectual projects and processes digitally visible and who invites and encourages ongoing criticism of their work and secondary uses of any or all parts of it--at any stage of its development." In both of these descriptions, there is no clear necessity for the scholar to value democratization, human rights, equality, and so on, and we should consider the possibility that scholars engage in open scholarly practices for a variety of reasons that may not be entirely noble (Veletsianos, 2012).

While open scholarly practices may share some of these noble goals (e.g., providing access to scholars who could not otherwise afford access to recently published research), scholars and institutions need to evaluate the purposes and functions of scholarship and take part in devising systems that reflect and safeguard these values of scholarly inquiry. For instance, the development of OA journals that charge authors (and by extension their institutions) to publish their manuscripts limits the diversity of voices in the scholarly process to those able to pay for publication. As with those in any community, scholars engaging in open scholarship are susceptible to the risks of making decisions about the future of their community which may be arbitrary, prejudiced, or otherwise harmful to the community's well-being, and, thus, scholars should be vigilant and reflective of their digital and open practices as these practices continue to emerge and develop. Such vigilance should focus both on determining who profits from such practices and who is excluded from them so as to combat both under-use by some (e.g., those lacking entry to or knowledge of useful networks) and over-use or exploitation by those with the wealth, power, and prestige necessary to effectively strip mine sources (c.f. Chander \& Sunder, 2004). While solutions to these problems may not be simple, forward-thinking approaches to proactive prevention with regard to the protection of scholarly freedom, and the upholding of these early-adopted ideals, are superior to post facto reparation.

To illustrate further, massive open online courses (MOOCs) were originally designed as moral imperatives and alternatives to traditional higher education, as attempts to offer free education that was co-created with learners (McAuley, Stewart, Siemens, \& Cormier, 2010). In this formulation, MOOCs were flexible enough to offer self-directed learners the ability to define for themselves the types of outcomes they desired, while at the same time offering opportunities for communal learning (Rodriguez, 2012). During 2011-2012, we saw bur- 
geoning interest in distance education by entrepreneurs, investors, and universities, and a resulting appropriation of MOOCs followed, such that the original MOOCs offered by Siemens, Downes, Cormier vis-à-vis the ones popularized by initiatives such as Coursera and Udacity share little resemblance other than the fact that they are freely available online courses. While the mass media celebrated the disruptive nature of online education and the death of higher education institutions (e.g., see McKenna, 2012 in The Atlantic, and Lewin, 2012 in the New York Times), a potential future defined by Coursera- and Udacity-type courses contrasts starkly with the narrative of MOOCs as flexible and empowering courses.

Many contemporary MOOCs can be more appropriately described as commodified education, rather than the type of open education initiatives suggested by their acronym. A clear example of this commoditization can be found in the rapid adoption of business-oriented models of distance education. While the intention of distance education enthusiasts and scholars from the inception of the field was to devise approaches to provide learning opportunities to individuals who could not otherwise physically attend educational institutions, such as learners who live in remote geographical areas (Davis, 2000), distance education is increasingly characterized as a product to be packaged and reused for efficient delivery to massive numbers of students (c.f. Noble, 2002; Wilson, Parrish, \& Veletsianos, 2008). While Coursera, Udacity, and EdX allow access to educational opportunities, this argument conceals the fact that (a) the type of education offered by these initiatives appears to be reserved for students who are intrinsically motivated, self-directed, and have the necessary prior knowledge to succeed; and (b) education has goals broader than effectiveness and efficiency, namely engagement and social justice (Wilson, Parrish, \& Veletsianos, 2008). In the words of Stewart (2012, ๆ22), "the problem with EdX is that, scale and cost aside, it IS essentially a traditional learning model revamped for a new business era."

Given these dichotomies, we should consider whether current implementations of open scholarship and open education (e.g., in the form of MOOCs) hold true to the ideals of democratization, equality, and justice or whether organizations might be appropriating the garb of open education without necessarily embracing the ideals of its founders.

\section{Assumption \#2: Emphases on Digital Participation for En- hanced Outcomes}

While technological advances may enable scholars efficient access to up-to-date information, networks of colleagues, and the potential to connect and network with diverse audiences, scholars need to develop an understanding of participatory cultures in order to take full advantage of open scholarship. For example, scholars need to develop an understanding of the affordances of the participatory web for scholarship and consider the implications of online identity and digital participation (c.f. Coiro, Knobel, Lankshear, \& Leu, 2008).

To participate productively in scholarly networks online, scholars not only need to understand the participatory nature of the Web, they also need to develop the social and digital literacies and skills essential for effective engagement with such networks. Unequal access to technology and/or lack of digital literacies is referred to as the participation gap (c.f. 
Jenkins et al., 2006). In the context of open scholarship, the participation gap may refer to those scholars and learners who participate in networked spaces and are able to take advantage of digital literacies to advance their learning, teaching, research, and career (e.g., learning new teaching approaches, bringing their research to the attention of broad audiences, organizing colleagues to tackle important professional issues) vis-à-vis those who have had no exposure to participatory cultures or who do not have the essential literacies to engage in such activities online. Rheingold (2010) is convinced that individuals need literacies affording them to decode and encode digital information. These literacies relate to attention, participation, collaboration, network awareness, and critical consumption (Rheingold). Without access to these literacies, contemporary scholars and learners will be ineffective participants in online spaces. Subscribing, following, and commenting on other scholars' blogs, for example, will at some point become too much of a time commitment. Nevertheless, scholars who are literate in digital matters are capable of devising ways to manage participation. For instance, the use of web services to alert scholars of newly published information relating to their research interests (e.g., through the use of Google Alerts) allows scholars to effortlessly remain current in developments in their field.

These issues introduce a need to redesign university curricula preparing future scholars to account for the changing nature of scholarship. In such curricula, we envision the teaching of tools to manage scholarly participation online and engagement with issues such as participatory cultures, open access publishing, information management, digital literacies, community-engaged scholarship, and scholarship evaluation metrics. In addition, we envision the development of learners' skills in situ, where their learning occurs in scholarly communities of practice, enabling scholars-in-training to understand both the content and the digital culture of open scholarship. For instance, digitally conscious scholars might employ the services of text-mining technologies (e.g., Google Alerts) to track mentions of their name or their publications such that they can take an active role in managing how they are represented online. These issues become increasingly important because, given the amount of information that exists online, including the publication of journals in digital form, the presence of university profiles, and the use of social media services for personal reasons, it is highly likely that scholars are already searchable and findable online.

\section{Assumption \#3: Co-Evolutionary Relationship between Tech- nology and Culture}

Technological innovations present opportunities for advancing how education and knowledge are negotiated and enacted, but we must recognize that technology, and social media in particular, are not neutral. Importantly, while contemporary discourse suggests that technology can transform and disrupt current educational and knowledge-creation processes (e.g., Mazoue', 2012), such discussion is largely guided by techno-enthusiasm and techno-determinism, focusing on viewing technology as a solution for cultural, systemic, and economic problems. However, technologies have embedded values and norms that may be in conflict with the values and norms of higher education cultures, advancing tensions and compromises.

For example, social media tools currently structure relationships and power structures in 
relatively flat and non-hierarchical manners (e.g., all connections are "friends," or all connections are "followers"), and such a stance may be incompatible with how relationships are structured in educational settings and other contexts offline (Veletsianos \& Kimmons, in press). At the same time, while participation in social media offers opportunities for connectedness and sharing of knowledge, we need to remain vigilant of the potential that social media might reinforce existing structures and norms. The tendency to connect with similar or like-minded individuals online as offline, what Thelwall (2009) calls homophily, means that social media may not foster diverse spaces for knowledge exchange and negotiation, leading instead to "echo chambers," a situation in which we share knowledge and perspectives with individuals who already share the same views as ourselves. At the same time, social media may shape the information that scholars access online via algorithms that are intended to support personalization but have the side effect of blinding users to diversity and encouraging uniformity. Pariser (2011) describes this phenomenon as the "filter bubble" and presents a convincing array of examples in which Internet tools have limited users' exposure to diverse information because web algorithms are designed to retrieve information that they deem relevant to the user (i.e., that which confirms prior behavior).

Given the fact that various technologies are negotiated spaces with embedded values, we should recognize that practices developing in conjunction with emergent technologies (e.g., Facebook, Twitter, Google) will be influenced by the embedded values of those technologies and that not all of these influences may be positive. For example, though Google Search may give scholars quick access to a wide array of open resources, the presentation of such resources might be biased to support the researcher's opinions, thereby hiding conflicting evidence. Additionally, though Twitter might allow researchers to follow one another and discuss topics of interest, such discussions may go unchallenged if participants are only followed by those who have similar educational training and beliefs.

\section{Assumption \#4: Practicality and Effectiveness for Achieving Scholarly Aims}

Though open scholarship may offer some clear benefits to improve scholarly efficiency and to practically address perennial problems in scholarly institutions (e.g., data sharing, research dissemination), such practices may also open the door to new dilemmas and make some aspects of current practice less efficient. For example, authors argue that the volume of information online has skyrocketed (Aro \& Olkinuora, 2007) and that the information age has produced a data "deluge" (Baker, 2008) or "explosion" (Delen \& Al-Hawamdeh, 2009). Though information overload is hardly a new concept (Rosenberg, 2003), due to the increasing availability of scholarly publications online, the data trails left behind by scholars when participating in social media, and the ease with which scholars can access resources from a diverse range of sources (e.g., from YouTube, to the New York Times, to this journal), scholars may come to face a personal information management challenge that entails (a) keeping up-to-date with newly published information, (b) filtering information, (c) rapidly differentiating between helpful and irrelevant information, and (d) saving helpful information for future retrieval. In other words, though open practices may make some aspects of scholarly practice more efficient (e.g., information sharing), such efficiency may 
create bottlenecks for other aspects of scholarly endeavor (e.g., differentiating between important and peripheral information).

To overcome this challenge, scholars need to develop skills, devise methods, and use technologies to manage (e.g., efficiently collect, categorize, and retrieve) digital information pertinent to their work and their digital participation. RSS readers and aggregators for example are viable solutions to information management challenges. RSS readers are applications that individuals can use to subscribe to feeds (e.g., blogs). These applications monitor feeds and download new content when it becomes available. Because RSS feeds download content to a central location as it becomes available, the user no longer needs to visit sites in search of content that is of interest to him/her. Scholars can use such applications to efficiently retrieve and archive digital information relevant to their professional interests via blogs, twitter feeds, journal feeds, and other sources of continuously updated information.

However, merely developing digital literacies, effectively using technologies, and participating in online scholarly communities does not mean that scholars will necessarily become efficient or equal participants in online spaces. Social stratification and exclusion in online environments and networks is possible, especially if scholars do not understand the cultural norms of networked participation. While digital literacies and an understanding of social technologies may enable scholars to engage in open scholarship, it does not necessarily follow that participation will be without perils or inequities. Where there is freedom to share and collaborate, there is often also freedom to abuse and exploit, so we should be careful not to indulge in idealized notions of participation, sharing, and openness that may be misguided. As Chander and Sunder (2004, p. 1332) point out when discussing what they term the romance of the public domain,

[c]ontemporary scholarship extolling the public domain presumes a landscape where each person can reap the riches found in the commons [equally] ... [b]ut, in practice, differing circumstances - including knowledge, wealth, power, and ability - render some better able than others to exploit a commons.

Thus, in the case of open scholarship, issues surrounding the provision of MOOCs, use of open access journals, accessibility and use of OER, participation in scholarly networks, and use of social media by diverse audiences will arise and should be a matter of concern for participants when considering who profits from, and can efficiently and practically use, their collaborative or shared work. As a simple example of this issue, while we can advocate that individuals should publish in OA journals or that they should use social media in their professional practice, we must recognize that if we engage professionally with these practices ourselves, our advocacy comes from a position of power and we might be better positioned to benefit from these practices than others whose individual circumstances prevent them from fully adopting such practices. 


\section{Conclusion}

In this paper, we identified a number of assumptions of the open scholarship movement and highlighted challenges associated with the aspirations of broadening access to education and knowledge through openness. We noted that even though openness and open scholarship have generated positive outcomes for those who enact and participate in such practices, individuals in the field infrequently critique their assumptions. The assumptions we identified suggest that open scholarship

- is rooted in an ethical pursuit of democratization, human rights, equality, and justice;

- highlights the importance of digital participation;

- is treated as co-evolutionary with technological advances;

- is considered as an approach capable of achieving socially valuable scholarly aims.

Challenges facing open scholarship are associated with each one of these assumptions. Examples include the misappropriation of open scholarship; the need for scholars developing social and digital literacies; the consideration that technology is neither neutral, nor a single solution to problems facing education and scholarship; and the consideration that open scholarship introduces new dilemmas relating to power, fairness, and equity.

In the introduction of our paper, we noted that Friedman (2005) argued that digital technologies and open source initiatives have contributed to the development of an even playing field between nations, groups, and individuals. Friedman however also noted that there is no guarantee that technologies will be used for the benefit of humanity, as he argues that the disempowered live in a flat world, but "don't have the tools or the skills or the infrastructure to participate in any meaningful or sustained way" (p. 382). Open scholarship has the potential to enhance scholarly endeavors, but it requires paradigmatic shifts in the ways that we think about education, knowledge, learning, teaching, and research. It also requires shifts in the ways that we view our identity as scholars, in the ways we think about media, and in the ways that we think about social stratification. Future research should examine these issues using both theoretical and empirical approaches, reporting on both the challenges individuals face when engaging with open scholarship, their successes and failures, as well as any breakthroughs developed to address the challenges we identified. In the process of creating scholarly and educational systems for the future, we, as an education community, need to remain critical of the systems we are creating and question our assumptions and practices. While such systems might arise from the inadequacies and shortcomings of the status quo, this does not make them exemplar or just. 


\section{References}

Atkins, D., Seely Brown, J. \& Hammond, A. (2007). A review of the open educational resources (OER) movement: Achievements, challenges, and new opportunities (Report to The William and Flora Hewlett Foundation). Retrieved from http://www. hewlett.org/uploads/files/ReviewoftheOERMovement.pdf

Beer, D. D. (2008). Social network(ing) sites... revisiting the story so far: A response to danah boyd \& Nicole Ellison. Journal of Computer-Mediated Communication, 13(2), 516-529.

Binkley, R. C. (1935). New tools for men of letters. The Yale Review, 24, 519-537.

Bonk, C. J. (2009). The world is open: How Web technology is revolutionizing education. San Francisco, CA: John Wiley and Sons.

Boyer, E. (1990). Scholarship reconsidered: Priorities for the professoriate. Princeton, NJ: The Carnegie Foundation for the Advancement of Teaching.

Brody, T., \& Harnad, S. (2004). Comparing the impact of open access (OA) vs. non- OA articles in the same journals. D-Lib Magazine, 10(6).

Budapest Open Access Initiative (2002). Retrieved from http://www.soros.org/openaccess/read.shtml

Bull, G., Thompson, A., Searson, M., Garofalo, J., Park, J., Young, C., \& Lee, J. (2008). Connecting informal and formal learning experiences in the age of participatory media. Contemporary Issues in Technology and Teacher Education, 8(2), 100-107.

Burton, G. (2009). The open scholar. Academic Evolution blog. Retrieved from http:// www.academicevolution.com/2009/08/the-open-scholar.html

Carson, S., \& Schmidt, J. (May, 2012). The massive open online professor. Academic Matters. Retrieved from http://www.academicmatters.ca/2012/05/the-massiveopen-online-professor/

Caswell, T., Henson, S., Jensen, M., \& Wiley, D. (2008). Open content and open educational resources: Enabling universal education. The International Review Of Research In Open And Distance Learning, 9(1).

Chan, L. (2004). Supporting and enhancing scholarship in the digital sge: The role of open access institutional repository. Canadian Journal of Communication, 29(3). Retrieved from http://cjc-online.ca/index.php/journal/article/view/1455

Chander, A., \& Sunder, M. (2004). The romance of the public domain. California Law Review, 92(5), 1331-1373. 
Cohen, L. (2007). Social scholarship on the rise [Blog entry posted to Library 2.0: An Academic's Perspective]. Retrieved from http://liblogs.albany.edu/library20/2007/04/ social scholarship on the rise.html

Coiro, J., Knobel, M., Lankshear, C., \& Leu, D. (2008). Central issues in new literacies and new literacies research. In J. Coiro, M. Knobel, C, Lankshear, C., \& D. Leu (Eds.), Handbook of research on new literacies (p. 1-21). New York: Lawrence Erlbaum.

Couros, A. (2010). Developing personal learning networks for open and social learning. In Veletsianos G. (Ed.), Emerging technologies in distance education (p. 109-128). Edmonton, AB: Athabasca University Press.

Craig, I. D., Plume, A. M., McVeigh, M. E., Pringle, J., \& Amin, M. (2007). Do open access articles have greater citation impact? A critical review of the literature. Journal of Informetrics, 1(3), 239-248.

Davis, L. (2000). Electronic highways, electronic classrooms: Distance education in Canada. In M. B. Castellano, L. Davis, \& L. Lahache (Eds.), Aboriginal education: Fulfilling the promise (pp. 224-251). Vancouver, BC: UBC Press.

Davis, P. (2006, March). Do open-access articles really have a greater research impact? College \& Research Libraries, 67(2).

Davis, P., \& Fromerth, M. J. (2007). Does the arXiv lead to higher citations and reduced publisher downloads for mathematics articles? Scientometrics, 71(2), 203-215.

European Commission (2012). A reinforced European research area partnership for excellence and growth. Communication from the Commission to the European parliament. Retrieved from http://ec.europa.eu/research/science-society/document library/pdf 06/era-communication-partnership-excellence-growth en.pdf

Evans, J. A. (2008). Electronic publication and the narrowing of science and scholarship. Science, 321(5887), 395-399.

Evans, J. A., \& Reimer, J. (2009). Open access and global participation in science. Science, 323(5917), 1025.

Eysenbach, G. (2006). Citation advantage of open access articles. PLoS Biol, 4(5), e157.

Fini, A. (2009). The technological dimension of a massive open online course: The case of the CCKo8 course tools. International Review of Research in Open and Distance Learning, $10(5)$.

Friedman, T. L. (2005). The world is flat: A brief history of the twenty-first century. New York: Farrar, Straus, and Giroux. 
Furlough, M. (2010). Open access, education research, and discovery. The Teachers College Record, 112(10), 2623-2648.

Gargouri, Y., Hajjem, C., Larivière, V., Gingras, Y., Brody, T., \& Harnad, S. (2010). Selfselected or mandated, open access increases citation impact for higher quality research. Plos one, 5(10), e13636.

Garnet, F., \& Ecclesfield, N. (2011). Towards a framework for co-creating open scholarship. Proceedings of the Association for Learning Technologies Conference (ALT-C).

Getz, M. (2005). Open scholarship and research universities. Working Paper 0517, Department of Economics, Vanderbilt University. Retrieved from http://ideas.repec. org/p/van/wpaper/0517.html

Geser, G. (2012). Open educational practices and resources: OLCOS Roadmap 2012. Salzburg, Austria: Salzburg Research, EduMedia Group. Retrieved from http://www. olcos.org/cms/upload/docs/olcos roadmap.pdf

Greenhow, C. (2009). Social scholarship: Applying social networking technologies to research practices. Knowledge Quest, 37(4), 42-47.

Greenhow, C., \& Robelia, B. (2009a). Old communication, new literacies: Social network sites as social learning resources. Journal of Computer-Mediated Communication, 14(4), 1130-1161.

Greenhow, C., \& Robelia, B. (2009b). Informal learning and identity formation in online social networks. Learning, Media \& Technology, 34(2), 119-140.

Greenhow, C., Robelia, B., \& Hughes, J. (2009). Learning, teaching, and scholarship in a digital age: Web 2.o and classroom research: What path should we take now? Educational Researcher, 38(4), 233-245.

Hajjem, C., Harnad, S., \& Gingras, Y. (2005). Ten-year cross-disciplinary comparison of the growth of open access and how it increases research citation impact. IEEE Data Engineering Bulletin, 28(4), 39-47.

Hall, R. (2011). Triple crunch and the politics of educational technology. DMU Learning Exchanges blog. Retrieved from http://www.learnex.dmu.ac.uk/2011/06/o8/ triple-crunch-and-the-politics-of-educational-technology/

Heap, T., \& Minocha, S. (2012). An empirically grounded framework to guide blogging for digital scholarship. Research In Learning Technology, 20. doi:10.3402/rlt. v20io.19195

Henneken, E., Kurtz, M., Eichhorn, G., Accomazzi, A., Grant, C., Thomson, D., \& Murray, S. (2006). Effect of e-printing on citation rates in astronomy and physics. Journal 
of Electronic Publishing, 9(2).

Hilton, J., \& Wiley, D. (2010). Free: Why authors are giving books away on the Internet. TechTrends, 54(2), 43-49.

Houghton, J., \& Sheehan, P. (2006). The economic impact of enhanced access to research findings. Centre for Strategic Economic Studies Working paper, Victoria University, Melbourne. Retrieved from http://www.cfses.com/documents/wp23.pdf

Hoosen, S., (2012). Survey on governments' open educational resources (OER) policies (Report for UNESCO and the Commonwealth of Learning). Retrieved from http:// www.col.org/PublicationDocuments/Survey_On_Government_OER_Policies. pdf

Ipsos. (2011, July 14). Canada's love affair with online social networking continues. Retrieved from http://www.ipsos-na.com/news-polls/pressrelease.aspx?id=5286

Jenkins, H., Clinton K., Purushotma, R., Robinson, A.J., \& Weigel, M. (2006). Confronting the challenges of participatory culture: Media education for the 21st century. Chicago, IL: The MacArthur Foundation.

Kirkup, G. (2010). Academic blogging: Academic practice and academic identity. London Review of Education, 8(1), 75-84.

Kjellberg, S. (2010). I am a blogging researcher: Motivations for blogging in a scholarly context. First Monday, 15(8). Retrieved from http://www.uic.edu/htbin/cgiwrap/ bin/ojs/index.php/fm/article/view/2962/2580

Kop, R., \& Fournier, H. (2010). New dimensions to self-directed learning in an open networked learning environment. International Journal of Self-Directed Learning, $7(2), 2-20$.

Kuchma, I. (2008). Open access, equity, and strong economy in developing and transition countries: Policy perspective. Serials Review, 34(1), 13-20.

Kumashiro, K., Pinar, W., Graue, E., Grant, C., Benham, M., Heck, R., Scheurich, J., Luke, A., \& Luke, C. (2005). Thinking collaboratively about the peer-review process for journal-article publication. Harvard Educational Review, 75(3), 257-285.

Kurtz, M., \& Brody, T. (2006). The impact loss to authors and research. In N. Jacobs (Ed.), Open access: Key strategic, technical and economic aspects. Oxford: Chandos Publishing.

Laakso, M., Welling, P., Bukvova, H., Nyman, L., Björk, B.-C., \& Hedlund, T. (2011). The development of open access journal publishing from 1993 to 2009. PLoS ONE, 6(6), e20961. 
Lawrence, S. (2001). Free online availability substantially increases a paper's impact. $\mathrm{Na}$ ture Web debates. Retrieved from http://www.nature.com/nature/debates/e-access/Articles/lawrence.html

Lewin, R. (July, 2012). Universities reshaping education on the Web. The New York Times [electronic edition]. Retrieved from https://www.nytimes.com/2012/07/17/education/consortium-of-colleges-takes-online-education-to-new-level.html

Lewis, S. P. (2006). Open access articles have a greater research impact than articles not freely available. Evidence Based Library and Information Practice, 1(3), 57-59.

Lynch, C. A. (2003). Institutional repositories: Essential infrastructure for scholarship in the digital age. Portal: Libraries and the Academy, 3(2), 327-336.

Martindale, T., \& Wiley, D. A. (2005). Using weblogs in scholarship and teaching. TechTrends, 49(2), 55-61.

Mazer, J., Murphy, R., \& Simonds, C. (2007). I'll see you on "Facebook": The effects of computer-mediated teacher self-disclosure on student motivation, affective learning, and classroom. Communication Education, 56(1), 1-17.

Mazer, J., Murphy, R., \& Simonds, C. (2009). The effects of teacher self-disclosure via Facebook on teacher credibility. Learning, Media and Technology, 34(2), 175-183.

Mazoue', J. (in press). The deconstructed campus. Journal of Computing in Higher Education.

McAuley, A., Stewart, B., Siemens, G., \& Cormier, D. (2010). The MOOC model for digital practice (University of Prince Edward Island, Social Sciences and Humanities Research Council's Knowledge synthesis grants on the Digital Economy report). Retrieved from http://www.elearnspace.org/Articles/MOOC Final.pdf.

McKenna, L. (May, 2012). The big idea that can revolutionize higher education: 'MOOC.' The Atlantic [electronic edition]. Retrieved from http://www.theatlantic.com/ business/archive/2012/05/the-big-idea-that-can-revolutionize-higher-education-mooc/256926/

Mishra, P., Koehler, M. J., \& Kereluik, K. (2009). The song remains the same: Looking back to the future of educational technology. TechTrends, 53(5), 48-53.

Moed, H. F. (2006). The effect of "Open Access" upon citation impact: An analysis of ArXiv's condensed matter section. Journal of the American Society for Information Science and Technology, 58(13), 2145-2156.

Moran M., Seaman J. \& Tinti-Kane H. (2011). Teaching, learning, and sharing: How today's higher education faculty use social media for work and for play. Pearson 
Learning Solutions.

Munoz, C., \& Towner, T. (2009). Opening Facebook: How to use Facebook in the college classroom. Proceedings of Society for Information Technology \& Teacher Education International Conference (pp. 2623-2627).

Nardi, B. A., Schiano, D. J., \& Gumbrecht, M. (2004). Blogging as social activity, or, would you let 900 million people read your diary? Proceedings of the 2004 ACM conference on Computer supported cooperative work (pp. 222-231).

Neylon, C., \& Wu, S. (2009). Article-level metrics and the evolution of scientific impact. PLoS Biology, 7(11), e1000242.

Noble, D. (2002). Digital diploma mills: The automation of higher education. New York, NY: Monthly Review Press.

Norris, M., Oppenheim, C., \& Rowland, F. (2008). The citation advantage of open-access articles. Journal of the American Society for Information Science and Technology, 59(12), 1963-1972.

OECD (2007). Giving knowledge for free: The emergence of open educational resources. Retrieved from http://www.oecd.org/edu/ceri/38654317.pdf

Pariser, E. (2011). The filter bubble: What the Internet is hiding from you. London: Viking/ Penguin Press.

Pearce, N.,Weller, M., Scanlon, E., \& Kinsley, S. (2010). Digital scholarship considered: How new technologies could transform academic work in education. In Education, 16(1).

Rheingold, H. (2010). Attention, and other 21st-century social media literacies. EDUCAUSE Review, 45(5), 14-24.

Roblyer, M., McDaniel, M., Webb, M., Herman, J., \& Witty, J. V. (2010). Findings on Facebook in higher education: A comparison of college faculty and student uses and perceptions of social networking sites. The Internet and Higher Education, 13(3), 134-140.

Rodriguez, O. (2012). MOOCs and the AI-Stanford like courses: Two successful and distinct course formats for massive open online courses. European Journal of Open and Distance Learning, 15. Retrieved from http://www.eurodl.org/index. php? $\mathrm{p}=$ current\&article $=516$

Rosenberg, D.(2003). Early modern information overload. Journal of the History of Ideas 64(1), 1-9. 
Selwyn, N. (2011a). Social media in higher education. In Gladman, A., (Ed.), The Europa world of learning (pp. 1-9). London, UK: Routledge.

Selwyn, N. (2011b). Editorial: In praise of pessimism-the need for negativity in educational technology. British Journal of Educational Technology, 42(5), 713-718.

Stewart, B. (May, 2012). The problem with EdX. Inside Higher Ed. Retrieved from http:// www.insidehighered.com/blogs/university-venus/problem-edx

Trinidad, S. B., Fullerton, S. M., Bares, J. M., Jarvik, G. P., Larson, E. B., \& Burke, W. (2010). Genomic research and wide data sharing: Views of prospective participants. Genetics in Medicine, 12(8), 486-495.

Tufekci, Z. (2008). Grooming, gossip, Facebook, and MySpace. Information, Communication \& Society, 11(4), 544-564.

UNESCO (2002). Forum on the impact of open courseware for higher education in developing countries: Final report. Retrieved from http://unesdoc.unesco.org/ images/0012/001285/128515e.pdf

Veletsianos, G. (2010). A definition of emerging technologies for education. In G. Veletsianos (Ed.), Emerging technologies in distance education (pp. 3-22). Edmonton, AB: Athabasca University Press.

Veletsianos, G. (2012). Higher education scholars' participation and practices on Twitter. Journal of Computer Assisted Learning, 28(4), 336-349.

Veletsianos, G., \& Kimmons, R. (in press). Scholars and faculty members lived experiences in online social networks. The Internet and Higher Education.

Veletsianos, G., \& Kimmons, R. (2012). Networked participatory scholarship: Emergent techno-cultural pressures toward open and digital scholarship in online networks. Computers \& Education, 58(2), 766-774.

Veletsianos, G., \& Navarrete, C. (2012). Online social networks as formal learning environments: Learner experiences and activities. The International Review Of Research In Open And Distance Learning, 13(1), 144-166.

Walker, J. (2006). Blogging from inside the ivory tower. In A. Bruns \& J. Jacobs (Eds.), Uses of blogs. New York, NY: Peter Lang.

Weller, M. (2011). The digital scholar: How technology is transforming scholarly practice. London, UK: Bloomsbury Academic.

Wiley, D. (2003). A modest history of OpenCourseWare. Autounfocus blog. Retrieved from http://www.reusability.org/blogs/david/archives/oooo44.html

Wiley, D. (2006). Open source, openness, and higher education. Innovate 3(1). Retrieved 
from http://www.innovateonline.info/index.php?view=article\&id=354

Wiley, D. (2010). Open education. In M. K. Barbour \& M. Orey (Eds.), The foundations of instructional technology. Retrieved from http://projects.coe.uga.edu/ITFoundations/index.php?title=Open Education

Wiley, D., \& Hilton III, J. (2009). Openness, dynamic specialization, and the disaggregated future of higher education. The International Review Of Research In Open And Distance Learning, 10(5). Retrieved from http://www.irrodl.org/index.php/irrodl/article/view/768

Wiley, D., Hilton III, J., Ellington, S., \& Hall, T. (2012). A preliminary examination of the cost savings and learning impacts of using open textbooks in middle and high school science classes. The International Review Of Research In Open And Distance Learning, 13(3), 262-276.

Wiley, D., \& Green, C. (2012). Why openness in education? In D. Oblinger (Ed.), Game changers: Education and information technologies (pp. 81-89). Educause.

Wilson, B., Parrish, P., \& Veletsianos, G. (2008). Raising the bar for instructional outcomes: Towards transformative learning experiences. Educational Technology, 48(3), 39-44.

Zaugg, B. H., West, R. E., Tateishi, I., \& Randall, D. L. (2011). Mendeley: Creating communities of scholarly inquiry through research collaboration. TechTrends, 55(1), 32-36.

\section{Athabasca University}

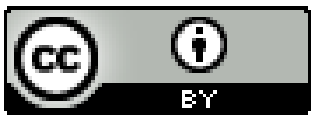

